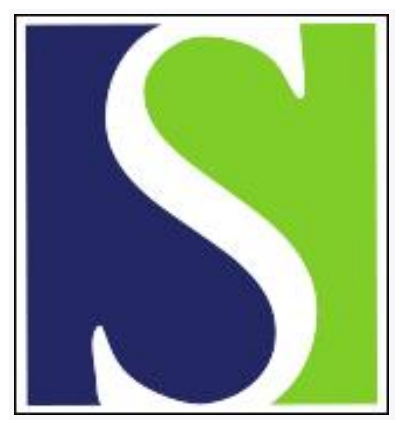

Scand J Work Environ Health 2003;29(6):468-477

https://doi.org/10.5271/sjweh.755

Issue date: Dec 2003

Work technique of nurses in patient transfer tasks and associations with personal factors

by Kjellberg K, Lagerström M, Hagberg M

Affiliation: Department for Work and Health, National Institute for Working Life, SE-113 91 Stockholm, Sweden. katarina.kjellberg@niwl.se

Refers to the following texts of the Journal: 1998;24(6):449-464 1998;24(2):85-97 1998;24(5):367-375

Key terms: age; gender; health-care worker; low back; musculoskeletal hazard; nurse; nursing; observation method; patient handling; patient transfer task; personal factor; work technique

This article in PubMed: www.ncbi.nlm.nih.gov/pubmed/14712855 


\title{
Work technique of nurses in patient transfer tasks and associations with personal factors
}

\author{
by Katarina Kjellberg, BSc, ${ }^{1,2}$ Monica Lagerström, PhD, ${ }^{3}$ Mats Hagberg, MD, ${ }^{2}$
}

\begin{abstract}
Kjellberg K, Lagerström M, Hagberg M. Work technique of nurses in patient transfer tasks and associations with personal factors. Scand J Work Environ Health 2003;29(6):468-477.
\end{abstract}

\begin{abstract}
Objectives Back disorders among nursing personnel are associated with the worktask of assisting patients during transfers. The objectives of the study were to explore the work technique applied by nursing personnel in patient transfer tasks and to determine whether different personal factors were associated with work technique safety.

Methods The work technique used by 102 nurses to perform two common patient transfer tasks in orthopedic wards, transfer higher up in bed and transfer from bed to wheelchair, was examined with the use of video recordings and an observation instrument. A work technique score was calculated for each performed transfer. It indicated the level of musculoskeletal safety and hazard for the nurse. The participants also filled out a questionnaire concerning different personal factors.

Results A variety of strategies was used by the nurses to perform the transfer tasks. Being older and suffering from low-back symptoms were factors associated with the use of poor work technique in both tasks. There was also an association between male gender and poor technique in transferring patients from bed to wheelchair.

Conclusions The results indicate an association between poor work techniques and low-back symptoms. Special attention should be paid to older nurses, nurses with low-back problems, and possibly also to male nurses when training programs on patient transfer technique are designed, as these groups seem to apply comparatively poor work techniques in patient transfer tasks.
\end{abstract}

Key terms age, health-care workers, low back, musculoskeletal hazards, nursing, observation method, patient handling, gender.

The worktask of assisting patients during transfers is a complex and arduous motor task that often implies high loads on the musculoskeletal system of nursing personnel $(1,2)$. The regular performance of patient transfers has been shown to be a risk indicator of low-back pain and reports of back injury (3-6). Low-back pain is the most frequent musculoskeletal disorder found among nursing personnel, and the 1-year prevalence has been reported to be between $45 \%$ and $75 \%$ (7-10). In comparison with other occupational groups, nursing personnel report considerably more back symptoms and back injuries $(11,12)$. The physical load in patient transfer work is, to a large extent, determined by workplace design (eg, the design of the rooms in a hospital ward), patient factors (eg, the weight and functional ability of patients), and work organization (eg, the number of patients that require assistance and the number of staff).
However, different persons are affected to varying degrees by similar external exposure. The way an individual nurse chooses to perform a transfer task probably also contributes to the physical load imposed on the nurse. Individual differences with respect to work technique may explain why some employees develop musculoskeletal disorders while others remain healthy (13, 14). However, in spite of several studies on the subject, the relation between work technique and physical load and musculoskeletal disorders has not been fully elucidated $(12,15)$.

It has been suggested that the concept work technique comprises the following two basic elements: the method used to carry out a worktask and the individual performance of a worktask (16). The first element, the method, represents general established work methods taught to workers (in the present study, patient transfer

1 Department for Work and Health, National Institute for Working Life, Stockholm, Sweden.

2 Department of Occupational Medicine, The Sahlgrenska Academy at Göteborg University, Göteborg, Sweden.

3 Department of Nursing, Karolinska Institute, Stockholm, Sweden.

Reprint requests to: Ms Katarina Kjellberg, Department for Work and Health, National Institute for Working Life, SE-113 91 Stockholm, Sweden. [E-mail: katarina.kjellberg@niwl.se] 
methods taught to nursing personnel during training programs). The second element, individual performance, refers to individual variations when a given transfer task is executed or a given transfer method is used, and we focused on this second element in our study.

A person's choice of a work technique is limited by both external and personal factors. External factors, for example, a limited space to move in, a nonadjustable hospital bed, a heavy patient, and time pressure, will limit the selection of the work technique used. Different workplace designs, work situations, and work organizations allow a different number of degrees of freedom for the worker's choice. Work technique is presumably also governed by personal factors (eg, age, gender, anthropometrics, motor and physical capacity, physical exercise habits, work experience, training in the particular worktask, knowledge, motivation, and problemsolving skills). For example, studies on the manual handling of loads have shown differences in gender $(17,18)$, age (19), and experience (20-24) with respect to work technique.

The objectives of the study were to explore the work technique applied by nursing personnel in patient transfer tasks and to determine whether different personal factors were associated with work technique safety.

\section{Material and methods}

\section{Definitions}

In our study the term nurse was used for nursing personnel assisting patients during transfers, and it included two work categories with different levels of education and training (registered nurses and enrolled nurses). Patient transfers were defined as worktasks in which nurses assist or lift a patient during transfers from one location to another (eg, transfer from bed to wheelchair) or from one position to another (eg, transfer higher up in bed).

\section{Participants}

Registered nurses and enrolled nurses with patient-care worktasks at orthopedic wards in five Swedish hospitals, nine wards in all, were asked to volunteer for the study. One hundred and two nurses, 86 women and 16 men, volunteered to participate out of the total number of 224 employed in the studied wards. Among these, there were 44 registered nurses and 58 enrolled nurses. The participants varied considerably in age, anthropometrics, and experience with patient transfer work (table 1).

The nonparticipants did not join the study either because they did not want to or because the time for the measurements did not suit their work schedules or because they were occupied with worktasks. Some of the nonparticipants were not on duty at the time of the measurements and could not be asked about participation, due to holiday, training, sick leave, or days off. For comparison of the participants and nonparticipants, the nonparticipants were asked to fill out the questionnaire used in the study, which was sent to them by mail. Out of the 122 eligible nonparticipating nurses, 95 completed the questionnaire. The participants and nonparticipants had the same characteristics except for the somewhat younger age, higher proportion of men and higher proportion of current low-back and shoulder symptoms among the participants (table 1).

The head nurses of the wards were informed, and they gave their approval for the study. All the participants were given oral and written information about the study and gave their written consent to participate. The study was approved by the regional ethics committees.

\section{Procedure}

The participants were asked to perform two standardized patient transfers, transfer from a supine position to higher up in bed and transfer from a sitting position on the edge of a bed to a wheelchair. The transfers took place in a room, arranged as a patient room for the purpose of the registrations, close to the orthopedic wards in each hospital. The participants left their ordinary

Table 1. Basic characteristics of the participants $(\mathrm{N}=102)$ and nonparticipants $(\mathrm{N}=95)$. $(\mathrm{BMI}=$ body mass index, $\mathrm{RN}=$ registered nurses, EN = enrolled nurses)

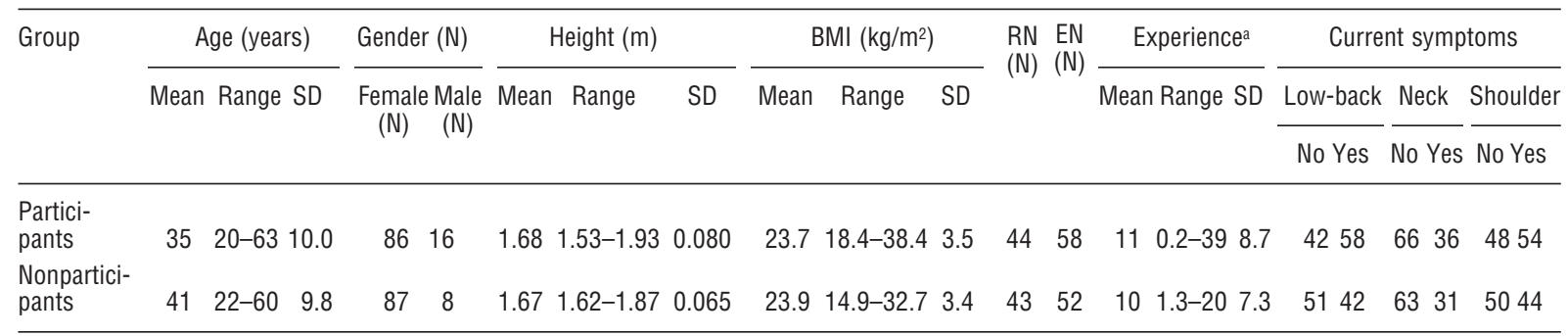

a Number of years performing patient transfer tasks. 
worktasks temporarily and wore their workclothes. Everything in the registration set-up was arranged in a standardized manner. Three healthy women of normal weight $(56,64$, and $67 \mathrm{~kg})$, two physiotherapists and one registered nurse, donned patient clothing and alternately acted as the patient. One person was available in the room to assist the participant during the transfer if requested. Five different transfer aids were accessible, a walking belt, a transfer board, an easyslide, a turntable, and an anti-slip cloth. An adjustable standard hospital bed was equipped with a draw sheet with a plastic underside and a monkey pole. The bed was adjusted to a constant height before each transfer task. The oral instruction to the participants was that they were to perform the transfers as if in a normal work situation in their own ward, but taking into consideration the situation in the room and the conditions given. The nurse was free to choose how to perform the transfer, including the option of using a transfer aid or not and of asking for assistance or not. Standardized information about the patient's diagnosis and function was given orally. The patient was an 80-year-old woman, with a left-side collum femoris fracture, who had undergone surgery the day before. She was allowed to load the hip in standing and walking as much as pain allowed. She was physically and mentally healthy apart from pain in both shoulders and dizziness due to surgery.

\section{Video recordings}

The patient transfers were recorded with two video cameras on stands. One camera faced the side of the bed, and one recorded slightly obliquely towards the foot-end of the bed. The whole body of the nurse was in the picture at all times, together with the scene of the transfer.

\section{Questionnaire}

Immediately after the registrations, the participants filled out a questionnaire concerning individual factors, experience with patient transfer work, previous training in patient transfer technique, physical exercise habits, and musculoskeletal symptoms. Musculoskeletal symptoms were rated according to a modified version of the Nordic Musculoskeletal Questionnaire (25). The questions and the response scales are presented in tables 2 and 3 .

\section{Observations and work technique assessment}

The video recordings of the patient transfers, 204 in all, were viewed by two observers, and the work technique was assessed for each transfer from registrations made with an observation instrument. The observation instrument had been developed earlier for the purpose of assessing work technique in patient transfer tasks with regard to musculoskeletal health and safety (26). The instrument consists of 24 items arranged according to the preparation phase, the starting position, and the actual performance of a transfer (table 4). A detailed description of the nurse's work technique, including actions taken to prepare for the transfer, the interaction with the patient, and any assistant co-worker, and the motor performance of the nurse, is provided. The validity and reliability of the instrument have been tested on video recordings made with one camera and shown to be mostly satisfactory (26). It was suggested to use two video cameras instead of one, to view the video film both at normal speed and in slow motion, and to develop more exact definitions of the observation items. These suggestions were incorporated into our study.

Two physiotherapists, independent of the project, were given 7 hours of training as observers by two experts. To finish the training, the two observers separately observed 6 transfers. The agreement between each observer's registrations and the registrations of the same transfers made jointly by the two experts was $89 \%$ and $92 \%$, respectively, for all the items of the six transfers together. This level of agreement was considered satisfactory.

The two observers separately observed about half of the 204 transfers each. The observers watched one transfer at a time by alternating between the views of the two video recordings on a video monitor. They were allowed to replay the videotapes several times and were advised to complement the viewing at normal speed with slow motion for the items of the actual performance phase.

\section{Data analyses}

The two studied patient transfer tasks, the transfer higher up in bed and the transfer from bed to wheelchair, were analyzed separately.

The work technique of the participants was described according to the 24 items in the observation instrument. In addition, an overall score was calculated for each transfer, as a measure of the work technique during the transfer with regard to musculoskeletal safety and hazard. The overall score was composed of a sum of the scores of 17 items from the observation instrument divided by the maximum possible score for the particular transfer observed. Seven items were not included in the calculation, due to the lack of consistent relations to musculoskeletal load which are valid in all transfer situations (table 4). The procedure for the calculation has been described earlier (26). The overall score assumes a value between 0 and 1 , where 1 is postulated to correspond to an ideal work technique. This work technique score was treated as the dependent variable. Descriptive data of the work technique score were presented as medians and the 25th and 75 th percentile. 
From the questionnaire, data on the personal factors age, gender, height, weight, occupation, number of years performing patient transfer tasks, training in patient transfer technique, practical training in the use of transfer aids, physical exercise habits, and musculoskeletal symptoms were used. From the weight and height, the body mass index (BMI) was calculated. These factors were treated as independent variables (tables 2 and 3). All the continuous variables and the variables with ordinal scales were categorized into two or three classes (tables 2 and 3). Age and BMI were categorized according to common methods in epidemiologic studies. The cutoff points for the variables physical exercise habits and current musculoskeletal symptoms were chosen from a previous study (27). The cutoff points for the remaining variables were determined from the distribution in the studied group.

Table 2. Work technique score for different categories of the independent variables for the two patient transfer tasks.

\begin{tabular}{|c|c|c|c|c|c|c|c|c|c|c|c|}
\hline \multirow[t]{3}{*}{ Independent variable } & \multirow[t]{3}{*}{ Response scale } & \multicolumn{5}{|c|}{ Transfer higher up in bed } & \multicolumn{5}{|c|}{ Transfer from bed to wheelchair } \\
\hline & & \multirow[t]{2}{*}{$\mathrm{Na}^{\mathrm{a}}$} & \multicolumn{4}{|c|}{ Score } & \multirow[t]{2}{*}{$\mathrm{Na}^{\mathrm{a}}$} & \multicolumn{4}{|c|}{ Score } \\
\hline & & & Median & $\begin{array}{l}\text { 25th } \\
\text { per- } \\
\text { cent- } \\
\text { ile }\end{array}$ & $\begin{array}{l}\text { 75th } \\
\text { per- } \\
\text { cent- } \\
\text { ile }\end{array}$ & $\begin{array}{c}\mathrm{P}- \\
\text { value }^{b}\end{array}$ & & Median & $\begin{array}{l}\text { 25th } \\
\text { per- } \\
\text { cent- } \\
\text { ile }\end{array}$ & $\begin{array}{l}\text { 75th } \\
\text { per- } \\
\text { cent- } \\
\text { ile }\end{array}$ & $\begin{array}{l}\text { P- } \\
\text { value }^{b}\end{array}$ \\
\hline Age & Continuous & & & & & & & & & & \\
\hline $\begin{array}{l}18-34 \text { years } \\
35-44 \text { years } \\
\geq 45 \text { years }\end{array}$ & & $\begin{array}{l}53 \\
32 \\
17\end{array}$ & $\begin{array}{l}0.82 \\
0.75 \\
0.72\end{array}$ & $\begin{array}{l}0.78 \\
0.65 \\
0.66\end{array}$ & $\begin{array}{l}0.93 \\
0.87 \\
0.81\end{array}$ & 0.001 & $\begin{array}{l}53 \\
32 \\
17\end{array}$ & $\begin{array}{l}0.75 \\
0.74 \\
0.66\end{array}$ & $\begin{array}{l}0.67 \\
0.60 \\
0.58\end{array}$ & $\begin{array}{l}0.80 \\
0.81 \\
0.74\end{array}$ & 0.048 \\
\hline $\begin{array}{l}\text { Gender } \\
\text { Female } \\
\text { Male }\end{array}$ & Dichotomous & $\begin{array}{l}86 \\
16\end{array}$ & $\begin{array}{l}0.81 \\
0.79\end{array}$ & $\begin{array}{l}0.70 \\
0.66\end{array}$ & $\begin{array}{l}0.93 \\
0.85\end{array}$ & 0.38 & $\begin{array}{l}86 \\
16\end{array}$ & $\begin{array}{l}0.73 \\
0.67\end{array}$ & $\begin{array}{l}0.64 \\
0.60\end{array}$ & $\begin{array}{l}0.80 \\
0.78\end{array}$ & 0.17 \\
\hline $\begin{array}{l}\text { Height } \\
\qquad \begin{array}{l}1.53-1.62 \mathrm{~m} \\
1.63-1.70 \mathrm{~m} \\
1.71-1.93 \mathrm{~m}\end{array}\end{array}$ & Continuous & $\begin{array}{l}31 \\
36 \\
35\end{array}$ & $\begin{array}{l}0.81 \\
0.82 \\
0.75\end{array}$ & $\begin{array}{l}0.69 \\
0.74 \\
0.68\end{array}$ & $\begin{array}{l}0.88 \\
0.93 \\
0.93\end{array}$ & 0.33 & $\begin{array}{l}31 \\
36 \\
35\end{array}$ & $\begin{array}{l}0.71 \\
0.75 \\
0.70\end{array}$ & $\begin{array}{l}0.64 \\
0.66 \\
0.60\end{array}$ & $\begin{array}{l}0.78 \\
0.80 \\
0.80\end{array}$ & 0.44 \\
\hline $\begin{array}{l}\text { Body mass index } \\
\quad<25 \mathrm{~kg} / \mathrm{m}^{2} \\
\geq 25 \mathrm{~kg} / \mathrm{m}^{2}\end{array}$ & Continuous & $\begin{array}{l}75 \\
25\end{array}$ & $\begin{array}{l}0.81 \\
0.79\end{array}$ & $\begin{array}{l}0.69 \\
0.70\end{array}$ & $\begin{array}{l}0.88 \\
0.93\end{array}$ & 0.70 & $\begin{array}{l}75 \\
25\end{array}$ & $\begin{array}{l}0.71 \\
0.75\end{array}$ & $\begin{array}{l}0.62 \\
0.65\end{array}$ & $\begin{array}{l}0.78 \\
0.81\end{array}$ & 0.24 \\
\hline $\begin{array}{l}\text { Occupation } \\
\text { Registered nurses } \\
\text { Enrolled nurses }\end{array}$ & Dichotomous & $\begin{array}{l}44 \\
58\end{array}$ & $\begin{array}{l}0.82 \\
0.78\end{array}$ & $\begin{array}{l}0.74 \\
0.67\end{array}$ & $\begin{array}{l}0.93 \\
0.88\end{array}$ & 0.021 & $\begin{array}{l}44 \\
58\end{array}$ & $\begin{array}{l}0.73 \\
0.72\end{array}$ & $\begin{array}{l}0.65 \\
0.60\end{array}$ & $\begin{array}{l}0.80 \\
0.79\end{array}$ & 0.35 \\
\hline $\begin{array}{l}\text { Number of years performing } \\
\text { patient transfer tasks }\end{array}$ & Continuous & & & & & & & & & & \\
\hline $\begin{array}{l}\leq 1 \\
\leq 5 \\
>5\end{array}$ & & $\begin{array}{l}12 \\
26 \\
64\end{array}$ & $\begin{array}{l}0.84 \\
0.82 \\
0.79\end{array}$ & $\begin{array}{l}0.66 \\
0.73 \\
0.69\end{array}$ & $\begin{array}{l}0.93 \\
0.88 \\
0.92\end{array}$ & 0.77 & $\begin{array}{l}12 \\
26 \\
64\end{array}$ & $\begin{array}{l}0.72 \\
0.74 \\
0.71\end{array}$ & $\begin{array}{l}0.66 \\
0.62 \\
0.63\end{array}$ & $\begin{array}{l}0.76 \\
0.79 \\
0.80\end{array}$ & 0.92 \\
\hline $\begin{array}{l}\text { Amount of training in patient } \\
\text { transfer techniques }\end{array}$ & Four-point & & & & & & & & & & \\
\hline $\begin{array}{l}\text { No training } \\
\text { A few hours } \\
\geq 1 \text { day }\end{array}$ & & $\begin{array}{l}10 \\
48 \\
39\end{array}$ & $\begin{array}{l}0.78 \\
0.81 \\
0.81\end{array}$ & $\begin{array}{l}0.65 \\
0.70 \\
0.71\end{array}$ & $\begin{array}{l}0.93 \\
0.93 \\
0.88\end{array}$ & 0.93 & $\begin{array}{l}10 \\
48 \\
39\end{array}$ & $\begin{array}{l}0.66 \\
0.73 \\
0.74\end{array}$ & $\begin{array}{l}0.59 \\
0.65 \\
0.64\end{array}$ & $\begin{array}{l}0.76 \\
0.80 \\
0.81\end{array}$ & 0.51 \\
\hline $\begin{array}{l}\text { Number of years since the } \\
\text { latest training occasion with } \\
\text { transfer technique }\end{array}$ & Continuous & & & & & & & & & & \\
\hline $\begin{array}{l}0-2 \\
3-6 \\
7-18\end{array}$ & & $\begin{array}{l}27 \\
29 \\
29\end{array}$ & $\begin{array}{l}0.86 \\
0.82 \\
0.79\end{array}$ & $\begin{array}{l}0.69 \\
0.70 \\
0.71\end{array}$ & $\begin{array}{l}0.93 \\
0.93 \\
0.82\end{array}$ & 0.36 & $\begin{array}{l}27 \\
29 \\
29\end{array}$ & $\begin{array}{l}0.73 \\
0.75 \\
0.75\end{array}$ & $\begin{array}{l}0.63 \\
0.66 \\
0.64\end{array}$ & $\begin{array}{l}0.79 \\
0.82 \\
0.80\end{array}$ & 0.54 \\
\hline $\begin{array}{l}\text { Practical training by instructor } \\
\text { in the use of transfer aids }\end{array}$ & Dichotomous & & & & & & & & & & \\
\hline $\begin{array}{l}\text { No } \\
\text { Yes }\end{array}$ & & $\begin{array}{l}53 \\
48\end{array}$ & $\begin{array}{l}0.82 \\
0.81\end{array}$ & $\begin{array}{l}0.70 \\
0.68\end{array}$ & $\begin{array}{l}0.91 \\
0.91\end{array}$ & 0.60 & $\begin{array}{l}53 \\
48\end{array}$ & $\begin{array}{l}0.73 \\
0.71\end{array}$ & $\begin{array}{l}0.64 \\
0.63\end{array}$ & $\begin{array}{l}0.78 \\
0.80\end{array}$ & 0.77 \\
\hline $\begin{array}{l}\text { Physical exercise during the } \\
\text { last } 3 \text { months }\end{array}$ & Six-point & & & & & & & & & & \\
\hline $\begin{array}{l}\text { No exercise } \\
\text { Regular exercise }\end{array}$ & & $\begin{array}{l}40 \\
61\end{array}$ & $\begin{array}{l}0.79 \\
0.82\end{array}$ & $\begin{array}{l}0.70 \\
0.70\end{array}$ & $\begin{array}{l}0.91 \\
0.92\end{array}$ & 0.33 & $\begin{array}{l}40 \\
61\end{array}$ & $\begin{array}{l}0.67 \\
0.76\end{array}$ & $\begin{array}{l}0.64 \\
0.64\end{array}$ & $\begin{array}{l}0.76 \\
0.81\end{array}$ & 0.047 \\
\hline
\end{tabular}

a $\mathrm{N}=$ number of participants.

${ }^{\mathrm{b}}$ For the differences between the categories. 
Table 3. Work technique score for the nurses without and with musculoskeletal symptoms for twopatient transfer tasks.

\begin{tabular}{|c|c|c|c|c|c|c|c|c|c|c|}
\hline \multirow[t]{3}{*}{ Independent variable } & \multicolumn{5}{|c|}{ Transfer higher up in bed } & \multicolumn{5}{|c|}{ Transfer from bed to wheelchair } \\
\hline & \multirow[t]{2}{*}{$\mathrm{Na}^{\mathrm{a}}$} & \multicolumn{4}{|c|}{ Score } & \multirow[t]{2}{*}{$\mathrm{Na}^{\mathrm{a}}$} & \multicolumn{4}{|c|}{ Score } \\
\hline & & Median & $\begin{array}{l}\text { 25th } \\
\text { per- } \\
\text { cent- } \\
\text { ile }\end{array}$ & $\begin{array}{l}\text { 75th } \\
\text { per- } \\
\text { cent- } \\
\text { ile }\end{array}$ & $\begin{array}{c}\mathrm{P}- \\
\text { value }^{\mathrm{b}}\end{array}$ & & Median & $\begin{array}{l}\text { 25th } \\
\text { per- } \\
\text { cent- } \\
\text { ile }\end{array}$ & $\begin{array}{l}\text { 75th } \\
\text { per- } \\
\text { cent- } \\
\text { ile }\end{array}$ & $\begin{array}{c}P- \\
\text { value }\end{array}$ \\
\hline \multicolumn{11}{|l|}{ Low-back symptoms } \\
\hline \multicolumn{11}{|l|}{ Current ${ }^{\mathrm{c}}$} \\
\hline Participants without symptoms & 42 & 0.81 & 0.73 & 0.93 & \multirow{2}{*}{0.19} & 42 & 0.76 & 0.71 & 0.82 & \multirow{2}{*}{0.001} \\
\hline Participants with symptoms & 58 & 0.79 & 0.68 & 0.89 & & 58 & 0.67 & 0.60 & 0.76 & \\
\hline \multicolumn{11}{|l|}{ During last 30 days ${ }^{d}$} \\
\hline Participants without symptoms & 41 & 0.81 & 0.71 & 0.88 & \multirow{2}{*}{0.86} & 41 & 0.76 & 0.67 & 0.82 & \multirow{2}{*}{0.007} \\
\hline Participants with symptoms & 52 & 0.80 & 0.68 & 0.93 & & 52 & 0.67 & 0.60 & 0.76 & \\
\hline \multirow{2}{*}{\multicolumn{11}{|c|}{$\begin{array}{l}\text { Neck symptoms } \\
\text { Current }{ }^{c}\end{array}$}} \\
\hline & & & & & & & & & & \\
\hline Participants without symptoms & 66 & 0.81 & 0.72 & 0.90 & \multirow{2}{*}{0.44} & 66 & 0.73 & 0.64 & 0.79 & \multirow{2}{*}{0.87} \\
\hline Participants with symptoms & 36 & 0.80 & 0.68 & 0.93 & & 36 & 0.74 & 0.61 & 0.81 & \\
\hline \multicolumn{11}{|l|}{ During last 30 days $^{d}$} \\
\hline Participants without symptoms & 65 & 0.81 & 0.71 & 0.88 & \multirow{2}{*}{0.60} & 65 & 0.73 & 0.64 & 0.79 & \multirow{2}{*}{0.56} \\
\hline Participants with symptoms & 30 & 0.78 & 0.68 & 0.93 & & 30 & 0.70 & 0.60 & 0.81 & \\
\hline \multicolumn{11}{|l|}{ Shoulder symptoms } \\
\hline Current ${ }^{c}$ & & & & & & & & & & \\
\hline Participants without symptoms & 48 & 0.81 & 0.73 & 0.88 & \multirow{2}{*}{0.74} & 48 & 0.73 & 0.62 & 0.79 & \multirow{2}{*}{0.92} \\
\hline Participants with symptoms & 54 & 0.81 & 0.68 & 0.93 & & 54 & 0.74 & 0.64 & 0.80 & \\
\hline \multicolumn{11}{|l|}{ During last 30 days $^{d}$} \\
\hline Participants without symptoms & 48 & 0.81 & 0.72 & 0.93 & \multirow{2}{*}{0.49} & 48 & 0.71 & 0.64 & 0.78 & \multirow[t]{2}{*}{0.56} \\
\hline Participants with symptoms & 46 & 0.81 & 0.69 & 0.88 & & 46 & 0.75 & 0.62 & 0.81 & \\
\hline
\end{tabular}

${ }^{\mathrm{a}} \mathrm{N}=$ Number of participants $\quad{ }^{\mathrm{b}}$ For the differences between the categories. $\quad{ }^{\mathrm{c}}$ Ten-point scale. $\quad{ }^{\mathrm{d}}$ Dichotomous scale.

Table 4. Observations of the work technique used by 102 nurses to transfer a patient higher up in bed (HB) and from bed to wheelchair (BW) according to 24 items of the observation instrument. The observations are given as the percentage of the study group. (NA = item not applicable for the transfer being observed)

\begin{tabular}{lrc}
\hline Items & $\begin{array}{r}\text { HB } \\
(\%)\end{array}$ & $\begin{array}{r}\text { BW } \\
(\%)\end{array}$ \\
\hline Preparation phase & & \\
1. Encouraged the patient to cooperate & 78 & 66 \\
2. Created space & 70 & 51 \\
3. Corrected the positions of objects that the patient & & \\
$\quad$ was transferred between & NA & 23 \\
4. Corrected the bed height & 70 & 87 \\
5. Used transfer aid(s) & 86 & 70 \\
6. Corrected the position of transfer aid $(s)$ & 4 & 3 \\
7. Asked for assistance & 67 & 72 \\
Starting position & & \\
8. Feet distance the same as or larger than hip width & 93 & 76 \\
9. Feet position at an angle $\left(\geq 45^{\circ}\right)^{\text {a }}$ & 74 & 64 \\
10. Gait position a & 18 & 47 \\
11. Left knee straight or slightly bent $\left(<45^{\circ}\right)^{\text {a }}$ & 95 & 96 \\
12. Right knee straight or slightly bent $\left(<45^{\circ}\right)^{\text {a }}$ & 99 & 97 \\
13. Back straight or slightly bent forward $\left(<45^{\circ}\right)$ & 71 & 93 \\
14. No curved back & 87 & 91 \\
Actual performance & & \\
15. Started after a starting signal & 80 & 34 \\
16. Stimulated the patient verbally a & 4 & 86 \\
& \multicolumn{2}{c}{ (continued) }
\end{tabular}

Table 4. Contunued.

\begin{tabular}{lrr}
\hline Items & $\begin{array}{r}\text { HB } \\
(\%)\end{array}$ & $\begin{array}{r}\text { BW } \\
(\%)\end{array}$ \\
\hline 17. Effort direction & 2 & 6 \\
$\quad$ Vertical & 31 & 1 \\
$\quad$ Horizontal & 67 & 93 \\
Both & & \\
18. Back motion ${ }^{\text {b }}$ & 30 & 90 \\
Sagital & 40 & 39 \\
Lateral bending & 14 & 59 \\
$\quad$ Twisting & 40 & 1 \\
$\quad$ No angular motion & & \\
19. Main motor components ${ }^{b}$ & 80 & 55 \\
$\quad$ Arms & 33 & 66 \\
$\quad$ Back & 58 & 43 \\
$\quad$ Legs & & \\
20. Use of legs if legs were the motor component a,b & 17 & 28 \\
$\quad$ Anteroposterior weight transfer & 83 & 19 \\
$\quad$ Lateral weight transfer & 2 & 49 \\
$\quad$ To crouch & 3 & 40 \\
$\quad$ To rise & 5 & 97 \\
21. Feet moved in direction of the movement & 98 & 90 \\
22. Smooth quality of motion & 92 & 17 \\
23. Transfer performed in one sequence a & 100 & 99 \\
24. No loss of balance & \\
\hline a This item did not contribute to the calculation of the work technique \\
score. \\
Registration of more than one category was allowed. & \\
\end{tabular}


The work technique scores were compared between the groups, according to the categories of the independent variables (eg, different age groups) using either the Mann-Whitney test (dichotomous variables) or the Kruskal-Wallis test (variables with three categories).

To explore the relationship between work technique and personal factors further, we carried out multiple logistic regression analyses. In these analyses the work technique score was dichotomized according to the distributions for each transfer into poor technique (the lower quartile) and safe technique (the three upper quartiles). Factors with P-values less than 0.25 for at least one of the studied transfer tasks in the univariate analyses were included in the logistic regression, with the exception of the factor low-back symptoms during the last 30 days. The same factors were included in the separate analyses for the two transfer tasks. Age and BMI were kept continuous in these analyses. The effects of personal factors on poor technique were estimated from the odds ratios and their $95 \%$ confidence intervals. Before the logistic regression analyses were performed, we checked for correlations between the independent variables. The only large correlation was observed between the variables age and number of years performing patient transfer tasks (Pearson correlation coefficient of 0.71).

All the statistical analyses were carried out with SPSS 10.0 for Windows (SPSS Inc, Chicago, IL, USA).

\section{Results}

\section{Work technique applied}

In preparation for the patient transfers, $78 \%$ of the nurses attempted to encourage the patient to cooperate during the transfer higher up in bed, for example, by informing the patient about what was going to happen (table 4 ), whereas $66 \%$ did so during the transfer from bed to wheelchair. Seventy percent of them created sufficient space for the transfer higher up in bed by removing objects that obstructed the performance, while almost half of them omitted this step before transferring the patient to the wheelchair. During the transfer to the wheelchair, only $23 \%$ of the nurses corrected the position of the wheelchair appropriately. Furthermore, from an ergonomic point of view, nearly one-third of the nurses did not correct the bed to an optimal height during the transfer to higher up in bed. Most of the nurses used transfer aids during the transfers. In addition, more than two-thirds asked for the assistance of a second person.

The actual performance of the transfer higher up in bed started, in most cases, with a starting signal (ie, a clear indication that the transfer was about to begin) given by the nurse to the patient and the assisting person, while during the transfer from bed to wheelchair such a signal was seldom given (table 4). Most of the nurses used a combined vertical and horizontal direction in their efforts to transfer the patient, even in the transfer higher up bed, which was a transfer in the horizontal plane. During the transfer higher up bed, $40 \%$ of the nurses did not make any pronounced back movements, while $90 \%$ moved their backs in the sagittal plane and $59 \%$ twisted their backs during the transfer from bed to wheelchair. Most of the nurses used their arms, and more than half also used their legs, performing weight transfers (ie, shifting their own body weight from one leg to the other) to move the patients higher up in bed. To transfer the patient from bed to wheelchair, the nurses mostly used their backs to generate force, but their arms and legs were also used.

The overall score of the participants' work technique during the transfer higher up in bed, calculated from the observations, ranged from 0.48 to 1.0 (median $0.81,25$ th percentile $0.70,75$ th percentile 0.92 ), while, for the transfer from bed to wheelchair, the range was 0.45 to 0.94 (median $0.73,25$ th percentile $0.64,75$ th percentile 0.79 ).

\section{Associations between work technique and personal factors}

Age, occupation, physical exercise habits, and low-back symptoms were associated with work technique safety according to the univariate analyses (tables 2 and 3 ). The young nurses received higher scores for their work technique than the older nurses in both tasks (table 2). The work technique differed between the two occupational groups with respect to the transfer higher up in bed, the registered nurses having a safer work technique (table 2 ). The group of participants who had performed physical exercise regularly during the last 3 months had higher work technique scores for the transfer from bed to wheelchair than the group who did not exercise (table 2 ). The work technique of the nurses experiencing ongoing low-back symptoms and those of the nurses who had experienced symptoms during the last 30 days were rated as less safe in the transfer from bed to wheelchair than the work technique of the nurses without such symptoms (table 3).

The multivariate analyses confirmed the associations for older age and current low-back symptoms with poor work technique during both tasks (table 5). In addition, there was an association between male gender and poor work technique in the transfer from bed to wheelchair.

\section{Discussion}

Different strategies were used by the nurses to perform the two patient transfer tasks. Older age and current 
Table 5. Odds ratios $(O R)$ with $95 \%$ confidence intervals ( $95 \%$ $\mathrm{Cl}$ ) from a logistic regression model for poor work technique (ie, a work technique score belonging to the lower quartile of the score distribution among the 102 participants). Separate analyses were made for transfers higher up in bed (HB) and transfers from bed to wheelchair (BW). The number of subjects with poor work technique was 25 for $\mathrm{HB}$ and 24 for $\mathrm{BW}$.

\begin{tabular}{|c|c|c|c|c|}
\hline \multirow[t]{2}{*}{ Independent variables } & \multicolumn{2}{|r|}{$\mathrm{HB}$} & \multicolumn{2}{|r|}{ BW } \\
\hline & $\mathrm{OR}$ & $95 \% \mathrm{Cl}$ & $\mathrm{OR}$ & $95 \% \mathrm{Cl}$ \\
\hline Age (10 years older) & 2.0 & $1.17-3.52$ & 2.3 & $1.24-4.17$ \\
\hline Gender (men versus women) & 1.8 & $0.38-8.40$ & 4.7 & $1.04-21.34$ \\
\hline Body mass index (1 unit higher) & 0.95 & $0.81-1.10$ & 0.83 & $0.68-1.01$ \\
\hline $\begin{array}{l}\text { Occupation (enrolled nurse } \\
\text { versus registered nurse) }\end{array}$ & 3.2 & $0.93-11.20$ & 2.0 & $0.57-6.96$ \\
\hline $\begin{array}{l}\text { Regular physical exercise during } \\
\text { the last } 3 \text { months }\end{array}$ & 1.4 & $0.45-4.14$ & 1.3 & $0.42-4.25$ \\
\hline Current low-back symptoms & 3.6 & $1.16-11.07$ & 3.7 & $1.17-11.41$ \\
\hline
\end{tabular}

low-back symptoms were factors associated with poor work technique. In addition, there was an association between male gender and poor technique in the transfer from bed to wheelchair.

The work technique of the nurses with current lowback symptoms and those of the nurses reporting lowback symptoms during the last 30 days was less safe than that of the nurses without symptoms. Many factors may have contributed to the observed differences. Current symptoms from the lower back at the time of the video recording may have influenced the performance of the patient transfers, through restrictions of movements due to pain avoidance, increased muscle tone and co-contraction, and fear of injury and increased pain. Johansson et al (28) have suggested a pathophysiological model behind work-related muscle pain syndromes. A vicious cycle is created in which musculoskeletal pain causes disturbances in proprioception, stiffness regulation, and motor control. Differences in lifting patterns between chronic low-back pain patients and healthy persons have been detected, the patients lifting more slowly and with less coordinated hip and knee movements (29). In a study of preferred low-back motion characteristics, patients with chronic low-back pain preferred to flex and extend the spine at a lower velocity through a decreased movement range when they were compared with healthy persons (30). An alternative explanation to the association between low-back symptoms and poor work technique could be that nurses with a poor technique are more likely to overload the low back and be stricken with low-back pain. In other words, poor work technique may have caused the low-back symptoms among the participants. A few prospective studies have shown that poor work technique constitutes a risk factor for musculoskeletal disorders and injuries $(13,14)$. Because of the cross-sectional design of our study, no conclusions could be drawn about such causal relations.
Age was associated with work technique safety in our study. The younger nurses adopted a safer work technique than the older nurses. One explanation could be that the participants' basic nursing education, which usually includes some training in patient transfer technique, was closer in time for the younger nurses than for their older colleagues. As the majority of the participants in our study had not been trained regularly at the workplace, the older nurses may have forgotten the transfer technique taught. The fact that aging is normally accompanied with a decline in both motor performance and physical capacity (31-34) could provide a further explanation for the older nurses' poorer work technique. However, the longer experience of the older nurses should imply better work skills, more expertise, and developed compensatory strategies. The role of experience in compensating for age-related decline in job performance is debated in the literature on age and work (33). It may be that aging nurses change their work methods and techniques in order to cope with heavy physical work (34). In a Canadian study, differences in work strategies between younger and older trash collectors were identified, the older trash collectors having adopted a slower workpace and more often having asked for help from co-workers than the younger ones (19). The older workers' work technique seemed to be adapted to a lower physical capacity induced by age. However, to our knowledge, no previous studies have been carried out to examine whether the work technique adopted by older or younger workers is the safest from a musculoskeletal point of view. Nygård et al (35) reported that store workers' improved work technique as a result of a training program in manual materials handling was not dependent on age. The prevalence of musculoskeletal disorders in physically demanding occupations increases with age (36). A higher prevalence of low-back symptoms among the older nurses may explain the age differences found for work technique. However, no relation between age and low-back symptoms was found in our study.

We found an association between gender and work technique safety, male nurses having lower work technique scores than female colleagues in transfers from bed to wheelchair. However, the number of men in our study was too low for reliable statistical estimates of the association to be obtained. A study on the lifting of a box (17) showed gender differences in work technique, the men having applied greater forward bending of the trunk at the beginning of the lift and having lifted with less synchronized hip-knee interjoint coordination than the women. It remains to be determined, however, if these differences solely reflect differences in strength and anthropometrics or if they also arise from differences in motor strategies between men and women. van der Beek et al (18) reported gender differences in exerted 
forces during pushing and pulling tasks performed by postal workers, differences which the authors could not explain by differences in anthropometrics and maximum physical capacity. They also found indications that the men and women used a slightly divergent work technique, in terms of a slower work pace for the women. In the cited studies, whether the gender differences found were related to the development of musculoskeletal disorders was not examined.

Contrary to our expectations, we found no association between the work technique score and experience in terms of number of years performing patient transfer tasks. Although differences in lifting strategies between experienced and inexperienced manual material handlers have been demonstrated in several studies (20-24), it is not clear whether the experienced workers' techniques were safer, from a musculoskeletal point of view, as the findings regarding the effects of the different lifting strategies on musculoskeletal load were not conclusive. A person's choice of work technique is probably a compromise between several objectives - not only to keep the musculoskeletal load low, but also to minimize energy expenditure, fatigue, pain and discomfort, to maintain balance, and to perform the worktask rapidly, safely and with high quality $(23,37-39)$.

Hospitals commonly use training programs in patient transfer technique to help prevent back problems among nurses. Neither the amount of such training nor how close in time the latest training occasion had occurred was found to influence work technique safety in our study. This finding is congruent with results from evaluations of training programs, which do not unanimously show positive results regarding the influence on back disorders $(6,12)$. However, a few studies have shown improvements in the skill of performing patient transfers after training programs (14, 40-42). Many programs are probably not sufficiently extensive in time. In addition, if the learned transfer skill is to be maintained, repetitions of the training on a regular basis are presumably necessary. In our study the majority of the participating nurses had received a total of less than 1 day of training during their career (table 2). Only nine nurses had participated in training for 1 week or more. The vast majority had not received any follow-up training, and none of the studied wards had routines for regularly training their staff in transfer technique, as reported by the participants and head nurses in interviews. The low contrast in training times may explain the lack of association with transfer skill.

It is noteworthy that most of the nurses made use of transfer aids and asked for the assistance of a co-worker during the standardized transfers. In other studies, it has been reported that transfer aids are seldom used by nurses $(43,44)$.

\section{Methodological considerations}

Orthopedic ward personnel were chosen for the study because it has been shown that they are subjected to an elevated risk of back injuries when compared with personnel in other hospital clinics $(3,45)$. Heavy and complicated patient transfers constitute a considerable proportion of the worktasks in orthopedic wards. Patients often undergo early rehabilitation after surgery and usually need assistance from personnel during this rehabilitation. Furthermore, casts and different contrivances that can impede and complicate the transfers are common.

The choice of the transfer tasks was based on earlier findings that transfers in bed and transfers to and from beds seem to be the most hazardous forms of transfer for nurses $(5,46)$. For the transfer higher up in bed, slightly higher scores were obtained than for the transfer from bed to wheelchair. This difference is probably due to the fact that the transfer from bed to wheelchair is more complicated in that it involves more than one operation (ie, standing up, turning, and sitting down) and therefore requires changes of the direction of force. A transfer higher up bed involves only one operation and one direction of force. Furthermore, the wheelchair may be located in the nurse's or patient's way and impede performance.

The work technique of the nurses was not studied under actual work conditions in the wards. Instead a room was specially arranged to simulate a patient room, and the patient was not a "real" patient, but a healthy person acting as an orthopedic patient with a specified diagnosis. The purpose was to standardize the external situation so that the variations in work technique would be due to personal factors only. If video recordings had been collected under actual work conditions, external factors such as patient characteristics (eg, weight, functional ability, and willingness to cooperate), workplace design (eg, availability of transfer aids), and organizational factors (eg, number of staff) would probably have accounted for a large proportion of the obtained variations. Furthermore, the work situation arranged was, in many ways, optimal in terms of, for example, space around the transfer, a relatively light and co-operative patient, the availability of transfer aids, and assistance from a co-worker, in order to minimize the risk of injury during the transfers. This "optimal" work situation may have reduced the variations in work technique, as it is easier to apply a safe technique in a situation with few obstacles, in comparison with a more-complicated transfer situation. However, the nurses were requested to try to act as if the situation were normal.

The work technique score has been suggested as a crude summary measure of performance with regard to musculoskeletal hazard and safety (26). It should be pointed out that the associations shown in this study are 
associations with this score (ie, associations with the safety of the work technique) and not with variations in the strategies applied when the transfers were performed. The limitations of the score have been discussed elsewhere (26). The relation of a particular score to the level of musculoskeletal safety and hazard is not known; it can only be interpreted in relation to another score. The higher the value, the safer the technique. Thus the division of the score into a poor technique and a safe technique with the cutoff point at the lower quartile was arbitrary and not based on any biological considerations or known risk levels. Furthermore, scores from different transfer tasks should be analyzed separately, as transfer tasks differ in complexity and degree of difficulty, and the differences influence the score, as has already been discussed. Therefore the dichotomization of the score was performed with different cutoff points for the two transfer tasks, according to the different distributions of the tasks.

\section{Concluding remarks}

Knowledge about the variation in nurses' work technique due to different personal factors is important if we are to understand how a safe work technique can be achieved from a musculoskeletal point of view, and it can be used in interventions aiming at preventing musculoskeletal disorders among nurses. The factors that were found to be associated with work technique safety (age, low-back symptoms, and gender) are all factors that cannot easily be used as preventive measures. Nevertheless, if younger and older nurses, persons with and without back pain, and women and men use a different technique when transferring patients, the differences should be considered when training programs in transfer technique and the use of transfer aids are designed. Our findings indicate that special attention towards older nurses, nurses with back problems, and possibly also male nurses seems justified. Finally, our results support the existence of an association between poor work technique and low-back symptoms even if the causality was not apparent due to the cross-sectional design of the study.

\section{Acknowledgments}

We would like to thank the nursing personnel in the hospital wards for taking time to participate and for their positive attitudes towards the project. We are also grateful for the support of the following persons: physiotherapists Helena Åkerman Tillegård, Ewa Gustafsson, Annika Thorsson, Gustav Jansson, Lena Jensen, Sofia Tor and Jenny Sterner, statistician Anna Ekman, and associate professor Lars Lindbeck.

\section{References}

1. Skotte JH, Essendrop M, Hansen AF, Schibye B. A dynamic 3D biomechanical evaluation of the load on the low back during different patient-handling tasks. J Biomech 2002;35:1357-66.

2. Marras WS, Davis KG, Kirking BC, Bertsche PK. A comprehensive analysis of low-back disorder risk and spinal loading during the transferring and repositioning of patients using different techniques. Ergonomics 1999;42:904-26.

3. Engkvist I-L, Wigaeus Hjelm E, Hagberg M, Menckel E, Ekenvall L. Risk indicators for reported over-exertion back injuries among female nursing personnel. Epidemiology 2000;11:519-22.

4. Jensen RC. Back injuries among nursing personnel related to exposure. Appl Occup Environ Hyg 1990;5:38-45.

5. Smedley J, Egger P, Cooper C, Coggon D. Prospective cohort study of predictors of incident low back pain in nurses. BMJ 1997;314:1225-8.

6. Lagerström M, Hansson T, Hagberg M. Work-related lowback problems in nursing [review]. Scand J Work Environ Health. 1998;24(6):449-64.

7. Smedley J, Egger P, Cooper C, Coggon D. Manual handling activities and risk of low back pain in nurses. Occup Environ Med 1995;52:160-3.

8. Knibbe JJ, Friele RD. Prevalence of back pain and characteristics of the physical workload of community nurses. Ergonomics 1996;39:186-98.

9. Alexopoulos EC, Burdorf A, Kalokerinou A. Risk factors for musculoskeletal disorders among nursing personnel in Greek hospitals. Int Arch Occup Environ Health 2003;76:289-94.

10. Josephson M, Lagerström M, Hagberg M, Wigaeus Hjelm E. Musculoskeletal symptoms and job strain among nursing personnel: a study over a 3 year period. Occup Environ Med 1997;54:681-5.

11. Engkvist I-L, Hagberg M, Lindén A, Malker B. Over-exertion back accidents among nurses' aides in Sweden. Saf Sci 1992;15:97-108.

12. Hignett $\mathrm{S}$. Work-related back pain in nurses [review]. J Adv Nurs 1996;23:1238-46.

13. Kilbom $\AA$, Persson J. Work technique and its consequences for musculoskeletal disorders. Ergonomics 1987;30:273-9.

14. Videman T, Rauhala H, Asp S, Lindström K, Cedercreutz G, Kämppi M, et al. Patient-handling skill, back injuries, and back pain: an intervention study in nursing. Spine 1989; $14: 148-56$.

15. Hsiang SM, Brogmus GE, Courtney TK. Low back pain (LBP) and lifting technique [review]. Int $\mathrm{J}$ Ind Erg 1997;19:59-74.

16. Kjellberg K, Lindbeck L, Hagberg M. Method and performance: two elements of work technique. Ergonomics 1998; 41:798-816.

17. Lindbeck L, Kjellberg K. Gender differences in lifting technique. Ergonomics 2001;44:202-14.

18. van der Beek AJ, Kluver BDR, Frings-Dresen MHW, Hoozemans MJM. Gender differences in exerted forces and physiological load during pushing and pulling of wheeled cages by postal workers. Ergonomics 2000;43:269-81.

19. Cloutier E. The effect of age on safety and work practices among domestic trash collectors in Québec. Saf Sci 1994;17:291-308.

20. Gagnon M. Box tilt and knee motions in manual lifting: two differential factors in expert and novice workers. Clin Bio- 
mech 1997;12:419-28.

21. Gagnon M, Plamondon A, Gravel D, Lortie M. Knee movement strategies differentiate expert from novice workers in asymmetrical manual materials handling. J Biomech 1996; 29:1445-53.

22. Authier M, Gagnon M, Lortie M. Handling techniques: the influence of weight and height for experts and novices. Int J Occup Saf Ergon 1995;1:262-75.

23. Authier M, Lortie M, Gagnon M. Manual handling techniques: comparing novices and experts. Int J Ind Ergon 1996;17:419-29.

24. Granata KP, Marras WS, Davis KG. Variation in spinal load and trunk dynamics during repeated lifting exertions. Clin Biomech 1999;14:367-75.

25. Kuorinka I, Jonsson B, Kilbom A, Vinterberg H, Biering Sørensen F, Andersson G, et al. Standardised Nordic questionnaires for the analysis of musculoskeletal symptoms. Appl Ergon 1987;18:233-7.

26. Kjellberg K, Johnsson C, Proper K, Olsson E, Hagberg M. An observation instrument for assessment of work technique in patient transfer tasks. Appl Ergon 2000;31:139-50.

27. Lagerström M, Hagberg M. Evaluation of a 3 year education and training program for nursing personnel at a Swedish hospital. AAOHN J 1997;45:83-92.

28. Johansson H, Sjölander P, Djupsjöbacka M, Bergenheim M, Pedersen J. Pathophysiological mechanisms behind workrelated muscle pain syndromes. Am J Ind Med 1999;Suppl $1: 104-6$.

29. Boston JR, Rudy TE, Lieber SJ, Stacey BR. Measuring treatment effects on repetitive lifting for patients with chronic low back pain: speed, style, and coordination. J Spinal Disord 1995;8:342-51.

30. McIntyre DR, Glover LH, Conino MC, Seeds RH, Levene JA. A comparison of the characteristics of preferred lowback motion of normal subjects and low-back-pain patients. J Spinal Disord 1991;4:90-5.

31. Enoka RM. Neuromechanical basis of kinesiology. 2nd ed. Champaign (IL): Human Kinetics; 1994.

32. Schmidt RA, Lee TD. Motor control and learning : a behavioral emphasis. 3rd ed. Champaign (IL): Human Kinetics; 1999.

33. Robertson A, Tracy CS. Health and productivity of older workers [review]. Scand J Work Environ Health 1998;24:8597.

34. de Zwart BCH, Frings-Dresen MHW, van Dijk FJH. Physical workload and the ageing worker: a review of the literature. Int Arch Occup Environ Health 1995;68:1-12.

35. Nygård C-H, Merisalo T, Arola H, Manka M-L, Huhtala H.
Effects of work changes and training in lifting technique on physical strain: a pilot study among female workers of different ages. Int J Ind Ergon 1998;21:91-8.

36. de Zwart BCH, Broersen JPJ, Frings-Dresen MHW, van Dijk FJH. Musculoskeletal complaints in The Netherlands in relation to age, gender and physically demanding work. Int Arch Occup Environ Health 1997;70:352-60.

37. Kilbom Å. Work technique—scientific and practical issues, definitions, and relation to musculoskeletal injuries. In: Proceedings of the 13th Triennial Congress of the International Ergonomics Association; vol 4. Tampere: Finnish Institute of Occupational Health; 1997. p 289-91.

38. Authier M, Lortie M. Assessment of factors considered to be important in handling tasks by expert handlers. Int $\mathrm{J}$ Ind Ergon 1993;11:331-40.

39. Kuorinka I, Lortie M, Gautreau M. Manual handling in warehouses: the illusion of correct working postures. Ergonomics 1994;37:655-61.

40. Feldstein A, Valanis B, Vollmer W, Stevens N, Overton C. The back injury prevention project pilot study: assessing the effectiveness of back attack, an injury prevention program among nurses, aides, and orderlies. J Occup Med 1993; 35:114-20.

41. Engels JA, van der Gulden JWJ, Senden TF, Kolk JJ, Binkhorst RA. The effects of an ergonomic-educational course: postural load, perceived physical exertion, and biomechanical errors in nursing. Int Arch Occup Environ Health 1998;71:336-42.

42. Johnsson C, Carlsson R, Lagerström M. Evaluation of training in patient handling and moving skills among hospital and home care personnel. Ergonomics 2002;45:850-65.

43. Garg A, Owen BD, Carlsson B. An ergonomic evaluation of nursing assistants' job in a nursing home. Ergonomics 1992; 35:979-95.

44. Owen BD, Welden N, Kane J. What are we teaching about lifting and transferring patients? Res Nurs Health 1999;22:313.

45. Yassi A, Khokhar J, Tate R, Cooper J, Snow C, Vallentyne S. The epidemiology of back injuries in nurses at a large Canadian tertiary care hospital: implications for prevention. Occup Med 1995;45:215-20.

46. Engkvist I-L, Hagberg M, Wigaeus Hjelm E, Menckel E, Ekenvall L, PROSA study group. The accident process preceding overexertion back injuries in nursing personnel. Scand J Work Environ Health 1998;24(5):367-75.

Received for publication: 15 January 2003 